\title{
Bilateral aplasia of the optic nerve in a cat
}

\author{
K. G. BARNETT AND T. D. GRIMES* \\ Comparative Ophthalmology Unit, Department of Veterinary Clinical Studies, School of Veterinary \\ Medicine, University of Cambridge
}

Congenital absence of the optic nerve in man is a very rare anomaly (Duke-Elder, r963, I964). In true cases the optic disc, optic nerve fibres, and central retinal blood vessels are absent on ophthalmoscopic examination. Hypoplasia of the optic nerve, which is also rare, occurs when some or all of the nerve fibres fail to develop and reach the disc. The condition may be unilateral or bilateral, and may be found in grossly malformed eyes or in those that are otherwise normal. Retinal vessels are present, however, although they may be greatly attenuated. The absence of retinal vessels necessarily involves a complete lack of vision.

Hypoplasia of the optic nerve has been described in the horse (Gelatt, Leipold, and Coffman, I969), cattle (Leipold and Huston, I968), and dogs (Saunders, I952; Gelatt and Leipold, 1971). Aplasia of the optic nerve has been recorded in the cat ((Abderhalden, I903; Zeeman and Tumbelaka, I916; Szymanski, 1926; Veenendaal, 1936) and the mouse (Bein, 1947). This report records the ophthalmoscopic and pathological features of bilateral aplasia of the optic nerve in a cat.

\section{Case report}

A 5-week-old male black-and-white long-haired kitten presented with a history of total blindness.

It was one of a litter of three born on a farm. The dam and two littermates were examined and found normal. The sire was unknown. The dam had produced several previous litters with no apparent abnormalities.

This kitten was well grown and, except for the ocular defect and a stumpy tail, was normal. Hearing was acute and when the animal was moving there was continouus and rapid head shaking. Ocular movements were few but there were intermittent episodes of nystagmus, both vertical and horizontal, rapid, of small excursion, and apparent only on ophthalmoscopic examination.

The two eyes were similar and normal in size (Fig. I). The ocular adnexa and the anterior segment, including the lens, were normal. The pupils were dilated, circular in shape, and did not respond to light. When the animal was active the pupils were maximally dilated but they constricted slightly at rest and exhibited hippus. In sleep the pupils were constricted and of the normal feline vertical slit shape.

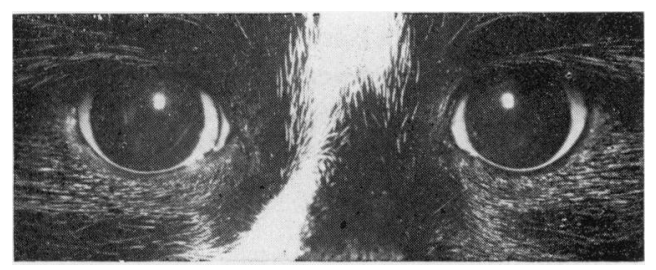

FIG. I Two eyes similar, normal in size, dilated pupils

Received for publication July 2, 1973

Address for reprints: K. C. Barnett, M.R.C.V.S., as above

* Present address: Department of Veterinary Medicine, University College, Dublin 
Slit-lamp examination showed fine strands of persistent pupillary membrane present in both eyes. They crossed sectors of the peripheral iris and were of the same yellow colour as the iris; they did not cross the pupil.

Ophthalmoscopic examination revealed absence of both optic discs and of the retinal blood vessels. The tapetum lucidum was present but appeared to be covered by a pale grey granular film (Fig. 2).

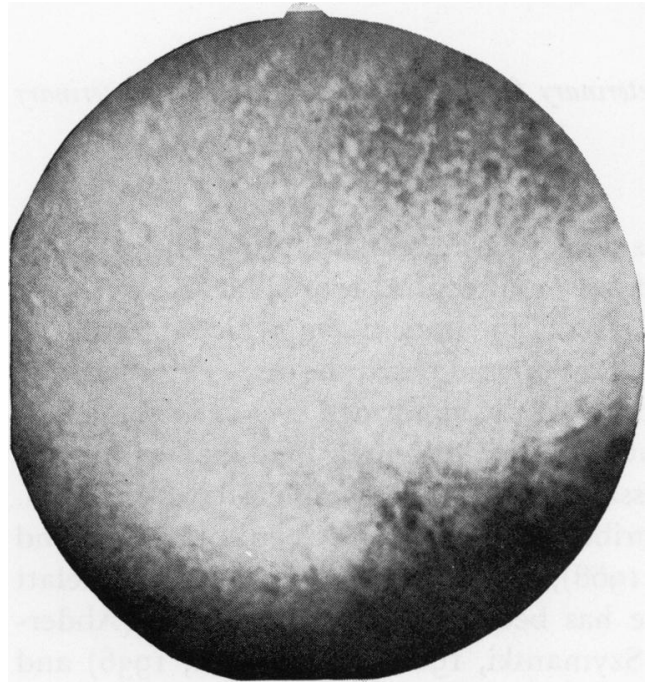

FIG. 2 Ophthalmoscopic appearance of retina

The tapetum nigrum was normal. Along the border between the tapetal and non-tapetal fundus were a few small roughly circular iridescent patches. In the right eye there was a dark wavy thread crossing the retina in an approximately horizontal position. In the left eye there was a cone-shaped translucent body in the anterior vitreous attached to the retina by fine strands arising near the margin of a small oval area which appeared to be a retinal hole.

\section{PATHOLOGY}

Post mortem examination revealed no abnormalities other than those in the eye and optic nerve.

Both optic nerves were represented by thin and fragile cotton-like strands, attached in the usual position to the posterior aspect of the globe, and were traced via the optic foramina to the brain, which they reached independently at a normal position but with no recognizable chiasm.

Histological examination of the retina revealed normal layer organization. The layer of rods and cones was essentially normal except for small foci where nuclei were present below the external limiting membrane. As expected, there were no ganglion cells and the Müller fibres appeared to be very prominent because of the spaces between them (Fig. 3). Rosette formation was present mainly in the peripheral retina but also in the central regions (Fig. 4). The retina extended well beyond the normal position of the ora serrata superiorly, and much further than the normal inferiorly; the rosettes were particularly evident in the superior peripheral retina.

Serial sections of the eye showed no penetration of the sclera or break in retina or choroid, which is the case when an optic nerve is present. Retinal blood vessels were absent from all sections examined. Transverse section of the strand of tissue representing the optic nerve revealed blood vessels and ciliary nerves but no optic nerve tissue. No optic tracts were seen in sections of the brain examined.

\section{Discussion}

Defective vision in young cats due to congenital abnormalities of the retina, optic nerves, and intraocular blood vessels has been reported previously (Abderhalden, 1903; Zeeman and Tumbelaka, ı916; Szymanski, r926; Veenendaal, I936; Jensen, I97 I). 


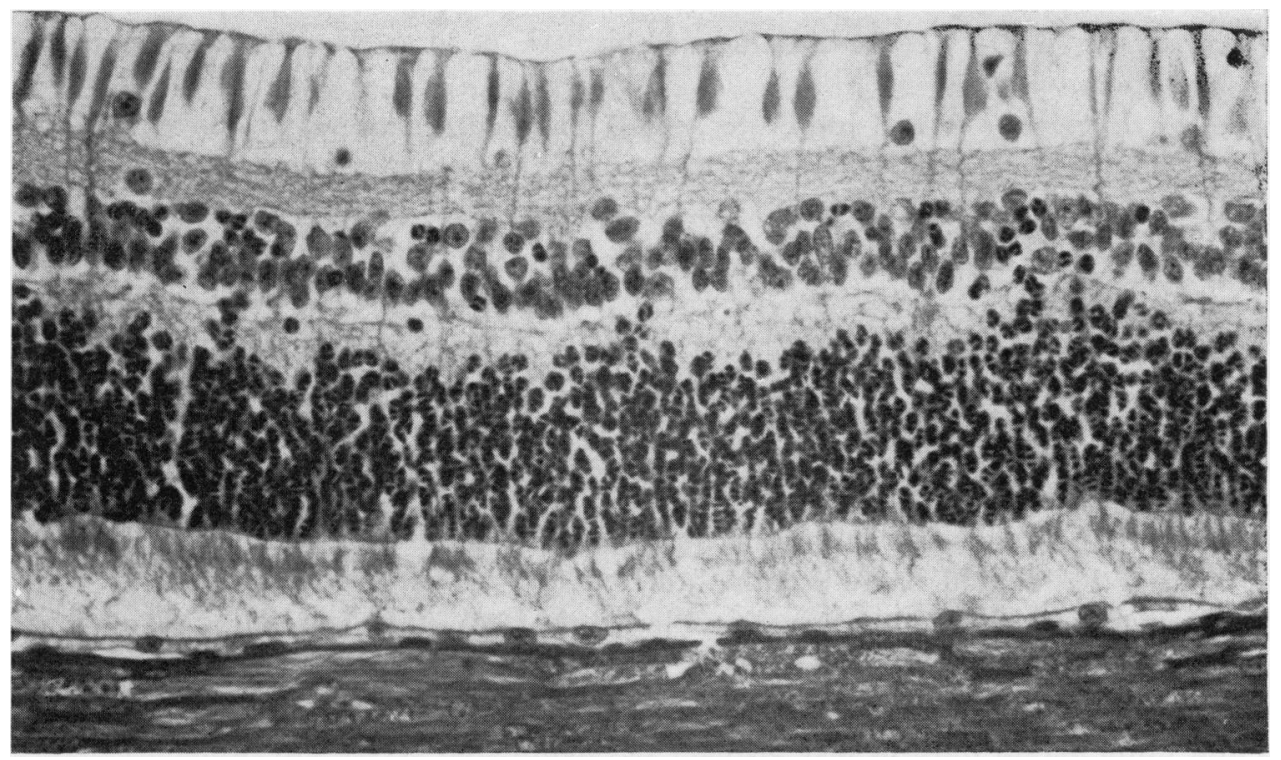

FIG. 3 Retina in region of tapetum lucidum. Haematoxylin and eosin. $\times 370$

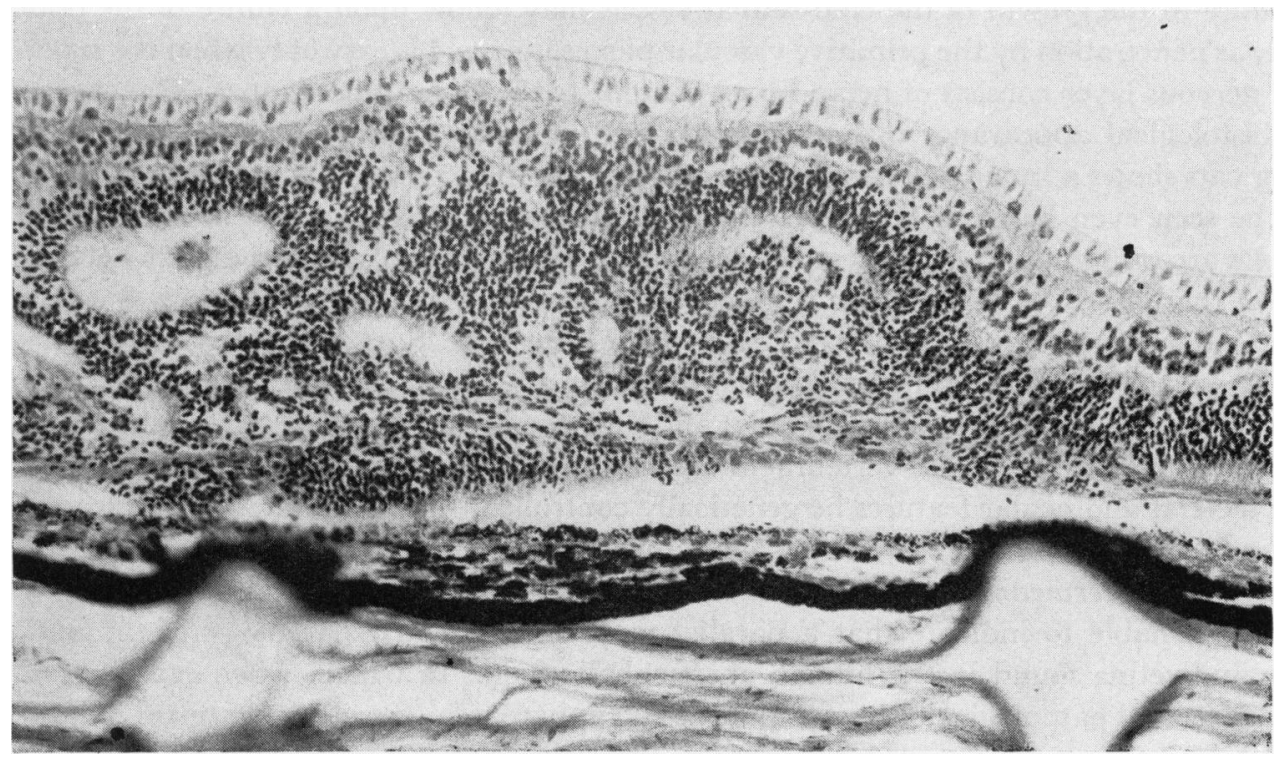

FIG. 4 Retina, showing rosette formation. Haematoxylin and eosin. $\times 150$

In cats the central retinal artery is invariably occluded and vestigial (Duke-Elder, I958), the retina deriving an arterial supply from a series of cilio-retinal arteries (Henkind, I966) which arise from the margin of the disc and appear to be branches of short posterior ciliary arteries which have penetrated the sclera (Prince, Diesem, Eglitis, and Ruskell, i96o). Similar vessels, when found in man, are formed developmentally by anastomosis of a central retinal vessel with a ciliary vessel which has penetrated the nerve fibres at the point of exit of the optic nerve (Mann, 1928).

The abnormalities present in the case described above consist of a failure in retinal differentiation, with absence of optic nerves and of a definitive cilio-retinal vascular supply 
to the retina. The primary cause of failure in this case, as in those previously described, remains unknown.

It has been suggested (Jerome and Foster, 1948) that complete aplasia of the optic nerve, with no papilla, retinal vessels, or retinal ganglion cell layer, may result when ingrowth of mesoderm into the foetal fissure is delayed, allowing this cleft to fuse completely and thus to prevent hyaloid or retinal vessels entering the eye. However, it appears unlikely that a defect which halts the development of the hyaloid system, whose function is to nourish the developing lens (Walls, 1942) and to complete a vascular supply to the embryonic iris, would leave an eye of normal size without recognizable evidence of developmental arrest of these structures (Abderhalden, ı093; Zeeman and Tumbelaka, 1916; Szymanski, I926). In the present case bilateral persistence of the pupillary membrane was found, while some parts were seen to be still patent when examined with the slit-lamp biomicroscope. It also seems probable, from the position and nature of the vitreal floater and localized retinal defects, that retinal tissue became adherent to part of the hyaloid and was ultimately drawn to lie with it in its normal position at the back of the lens. The case in which lens tissue was not found (Veenendaal, 1936) also showed lesions indicative of obliteration of the anterior chamber, and it must be doubted that the histological changes found in the retina and optic nerves were in fact primary developmental errors but rather secondary to a raised intraocular pressure.

Failure in the growth of the cilio-retinal vessels may follow upon a failure of the optic nerve, as penetration by the primitive vascular plexus involved is easy only when the superficial nervous layer consists of nerve fibres (Mann, 1928; Duke-Elder, 1963). The clinical and histological appearance of both nervous and vascular parts of the affected eyes of young cats shows a range which spans aplastic and atrophic change. A marked difference may be seen even between the affected eyes of the same individual (Szymanski); these changes are presumably of the same aetiology. The congenital aplasia of the optic nerve in mice of the 'Basle Waltzing' strain is inherited as an autosomal recessive defect. Bilateral and unilateral forms appear to be expressions of the same gene. Such quantitative difference in expression is common in inherited ocular defects in all species (Saunders, 1952). It seems remarkable that both Abderhalden (I903) and the present authors observed a gross reduction in the number of caudal vertebrae in cats affected with this ocular anomaly. Should these skeletal and ocular features be genetically controlled, their correlated effect suggests a close functional linkage between the genes involved.

Early and intermediate stages of this feline maldevelopment are not available, but it seems reasonable to indicate that a parallel may exist with the pathology of the optic nerve and retina found in the human anencephalic foetus in which, when examined at term, antenatal pathological processes produce an apparent failure of development (Mann, 1928).

Our thanks are due to Mr. and Mrs. J. M. Bowen, who referred this case and supplied the clinical history, to Drs. A. C. Palmer and W. F. Blakemore for advice on the histopathological sections, and to Mr. J. E. Payne for his technical assistance.

\section{References}

Abderhalden, в. (1903) Berl. Tierärztl. Wschr. No. 46, p. 709

BEIN, H. J. (1947) Ophthalmologica (Basel), 113, 12

DUKE-ELDER, s. (1958) “System of Ophthalmology", vol. I, p. 477. Kimpton, London. 
(1963) Idem, vol. 3, pt I, 'Embryology'

(1964) Idem, vol. 3, pt 2, 'Congenital deformities'

GElATt, K. N., and LEIPOLD, H. W. (197I) Canad. vet. F., 12, 9I

$\longrightarrow,-$, and cofrman, J. R. (1969) J. Amer. vel. med. Ass., 155, 627

HENKIND, P. (1966) Exp. Eye Res., 5, Io

JENSEN, H. E. (197 I) "Stereoscopic Atlas of Clinical Ophthalmology of Domestic Animals". Mosby,

Saint Louis

JEROME, B., and FORSTER, H. W. (1948) Arch. Ophthal. (Chicago), 39, 669

LEIPOLD, H. W., and huston, K. (1968) Path. Vet., 5, 407

manN, I. (1928) "The Development of the Human Eye". University Press, Cambridge

(1957) "Developmental Abnormalities of the Eye". British Medical Association, London

PRINCE, J. H., DIESEM, C. D., Eglitis, I., and Ruskell, G. L. (I96o) "Anatomy and Histology of the

Eye and Orbit in Domestic Animals". Thomas, Springfield, Ill.

SAUNDERS, L. z. (1952) Cornell Vet., 42, 67

SZyMANSKi. м, (1926) Bull. Soc. franc. Ophtal., 39, 265

veEnendaAl, H. (1936) T. Diergeneesk., 66, 260

WALLs, G. L. (1942) "The Vertebrate Eye and its Adaptive Radiation". Cranbrooke Institute of

Science, Bloomfield Hills, Mich. (Bull. no. 19)

zeeman, w. P. C., and tumbelaka, R. (1916) v. Graefes Arch. Ophthal., 91, 242 